\title{
The Dissociation between Early and Late Selection in Older Adults
}

\section{Citation}

Alperin, Brittany R., Anna E. Haring, Tatyana Y. Zhuravleva, Phillip J. Holcomb, Dorene M. Rentz, and Kirk R. Daffner. 2013. "The Dissociation Between Early and Late Selection in Older Adults." Journal of Cognitive Neuroscience 25, no. 12: 2189-2206.

\section{Published Version}

10.1162/jocn_a_00456

\section{Permanent link}

http://nrs.harvard.edu/urn-3:HUL.InstRepos:12605384

\section{Terms of Use}

This article was downloaded from Harvard University's DASH repository, and is made available under the terms and conditions applicable to Other Posted Material, as set forth at http:// nrs.harvard.edu/urn-3:HUL.InstRepos:dash.current.terms-of-use\#LAA

\section{Share Your Story}

The Harvard community has made this article openly available.

Please share how this access benefits you. Submit a story.

\section{Accessibility}




\title{
The Dissociation between Early and Late Selection in Older Adults
}

\author{
Brittany R. Alperin ${ }^{1}$, Anna E. Haring ${ }^{1}$, Tatyana Y. Zhuravleva', \\ Phillip J. Holcomb ${ }^{2}$, Dorene M. Rentz ${ }^{1}$, and Kirk R. Daffner ${ }^{1}$
}

\begin{abstract}
Older adults exhibit a reduced ability to ignore task-irrelevant stimuli; however, it remains to be determined where along the information processing stream the most salient age-associated changes occur. In the current study, ERPs provided an opportunity to determine whether age-related differences in processing task-irrelevant stimuli were uniform across information processing stages or disproportionately affected either early or late selection. ERPs were measured in young and old adults during a color-selective attention task in which participants responded to target letters in a specified color (attend condition) while ignoring letters in a different color (ignore condition). Old participants were matched to two groups of young participants on the basis of neuropsychological test performance: one using age-appropriate norms and the other using test scores not
\end{abstract}

\section{INTRODUCTION}

A critical mechanism for conserving neural resources and efficiently carrying out task demands is to limit the allocation of resources to stimuli that are supposed to be ignored. Research on selective attention suggests that, as individuals get older, they become much less proficient in managing this challenge. Behavioral data indicate that there is substantial age-related decline in the capacity to inhibit the processing of task-irrelevant events, which interferes with performance, as measured by RT and accuracy (de Fockert, Ramchurn, Van Velzen, Bergstrom, \& Bunce, 2009; Gazzaley et al., 2008; Lustig, Hasher, \& Zacks, 2007; West, 1999). In addition, functional imaging studies show that, compared with their younger counterparts, old participants appropriate excessive processing resources in response to stimuli that are supposed to be ignored (Gazzaley et al., 2008; Gazzaley, Cooney, Rissman, \& D’Esposito, 2005; Milham et al., 2002; McDowd \& Filion, 1992). One outstanding issue is to establish where along the information processing stream the most critical age-associated changes take place. The high temporal resolution of ERPs makes them particularly well suited to

\footnotetext{
${ }^{1}$ Harvard Medical School and Brigham and Women's Hospital, Boston, MA, ${ }^{2}$ Tufts University, Medford, MA
}

adjusted for age. There were no age-associated differences in the magnitude of early selection (attend-ignore), as indexed by the size of the anterior selection positivity and posterior selection negativity. During late selection, as indexed by P3b amplitude, both groups of young participants generated neural responses to target letters under the attend versus ignore conditions that were highly differentiated. In striking contrast, old participants generated a P3b to target letters with no reliable differences between conditions. Individuals who were slow to initiate early selection appeared to be less successful at executing late selection. Despite relative preservation of the operations of early selection, processing delays may lead older participants to allocate excessive resources to task-irrelevant stimuli during late selection. examine cognitive operations as they unfold over time and provides an opportunity to carefully investigate the relationship between markers of early and late selection.

Traditionally, selective attention has been classified in terms of early selection and late selection. Early selection involves the initial separation (i.e., early filtering) of stimuli in accordance with fundamental physical characteristics, such as location, orientation, or color (Kenemans, Smulders, \& Kok, 1995; Näätänen, 1992; Wijers, Mulder, Okita, Mulder, \& Scheffers, 1989; Looren de Jong, Kok, \& van Rooy, 1988; Broadbent, 1970). Late selection involves categorizing a stimulus as a member of the target set based on additional processing of physical, functional, or semantic properties (i.e., decision-making; Looren de Jong et al., 1988). In the current study, ERPs were used to investigate whether age-related changes in the allocation of resources to taskirrelevant stimuli were uniform across information processing stages or disproportionately affected either early or late selection. In the task employed, young (mean age $\sim 23$ years) and old (mean age $\sim 75$ years) adult participants were shown a series of red and blue letters, with specific letters designated as targets. Participants were told to respond to target letters in a designated color and to ignore stimuli in the other color. On the basis of the processing model developed from prior work (Daffner, Tarbi, et al., 2012; Daffner, Zhuravleva, et al., 2012), we 
expected that participants would initially select input on the basis of the most easily identifiable physical characteristic (color) and then continue to process more complex features (letter forms) of stimuli in the relevant color to identify targets (Daffner, Zhuravleva, et al., 2012; Looren de Jong et al., 1988; Hillyard \& Munte, 1984).

To appropriately interpret age-related changes in neural activity, it is important to minimize group differences in cognitive abilities and task performance. If not, observed differences between groups may be because of factors other than age (Haring et al., 2013; Daffner, Sun, et al., 2011; Riis et al., 2008; Daselaar \& Cabeza, 2005). Most studies have not explicitly addressed this challenge. Because of strong support for the idea that selective attention reflects top-down control mechanisms (Zanto, Rubens, Thangavel, \& Gazzaley, 2011; Rissman, Gazzaley, \& D'Esposito, 2009; Gazzaley et al., 2008; de Fockert, Rees, Frith, \& Lavie, 2001), we made an effort to match age groups in terms of executive capacity using two strategies. Consistent with suggestions in the aging literature, the first method matched groups according to performance relative to age-appropriate norms (i.e., percentile scores; Riis et al., 2008; Daffner et al., 2006, 2007; Daselaar \& Cabeza, 2005). One concern with this approach is that, although old and young participants may have comparable performance relative to age-matched norms, the nonadjusted scores of older participants on tests of executive function would be much lower than that of young participants. To address this issue, a second group of young adults was selected, whose performance on neuropsychological tests matched the non-age-adjusted scores of old participants.

The neural correlates of selective attention are often measured in terms of the difference in neural activity directed to physically identical stimuli under attend versus ignore conditions, which for ERPs is frequently indexed by the amplitude of components. Absent or minimal amplitude difference between these two conditions represents a failure of selective attention. It follows that larger differences in the size of the ERPs to stimuli under attend versus ignore conditions reflects the most advantageous response. This is supported by results from previous studies that have found that participants who perform better on experimental tasks involving selective attention generate larger differences in neural response between attend and ignore conditions (Gazzaley et al., 2005, 2008; Vogel, McCollough, \& Machizawa, 2005). ERPs also provide a measure of the speed by which processing operations are carried out, which is indexed by the onset, or more commonly the peak latency of components (Anderer, Semlitsch, \& Saletu, 1996; McCarthy \& Donchin, 1981).

In the current study, early selection was indexed by two major endogenous potentials that are measured in terms of the difference in activity between attend and ignore conditions: the anterior selection positivity (SP) and the posterior selection negativity (SN). These potentials exhibit an overlapping time course between $\sim 150$ and $350 \mathrm{msec}$ poststimulus presentation. The anterior
SP has been interpreted either as a frontally mediated index of the motivational salience of a stimulus based on task relevance (Riis et al., 2009; Potts \& Tucker, 2001) or as a marker of a detection process sensitive to stimulus features, such as color, orientation, or size, that have been specified by task instructions as being significant (Luck \& Hillyard, 1994). The posterior SN, which reflects the activity of feature selection areas of the extrastriate cortex, indexes the enhancement of sensory-perceptual processing of relevant stimulus features compared with irrelevant ones (Kopp, Tabeling, Moschner, \& Wessel, 2007; Hillyard, Teder-Salejarvi, \& Munte, 1998; Harter \& Aine, 1984). Late selection was indexed by the P3b component, which usually peaks between $\sim 400$ and $700 \mathrm{msec}$, and reflects either the categorization of an event as a target or the updating of working memory once an event has been categorized (Daffner, Chong, et al., 2011; Kok, 2001; Sirevaag, Kramer, Coles, \& Donchin, 1989; Donchin \& Coles, 1988; Wickens, Kramer, Vanasse, \& Donchin, 1983). Although many studies on aging have examined either early or late selection (Hahn, WildWall, \& Falkenstein, 2011; Zanto, Hennigan, Ostberg, Clapp, \& Gazzaley, 2010; de Fockert, Ramchurn, van Velzen, Bergstrom, \& Bunce, 2009; Fjell \& Walhovd, 2004), surprisingly few studies have examined both or directly compared age-related changes in these processes (Gazzaley et al., 2008; Talsma, Kok, \& Ridderinkhof, 2006; Czigler, 1996).

Several theories of cognitive aging propose the existence of a common mediating factor that has a widespread impact on information processing (Ghisletta \& de Ribaupierre, 2005; Braver et al., 2001; Li \& Lindenberger, 1999; Baltes \& Lindenberger, 1997; Hasher \& Zacks, 1988). For example, the inhibitory deficit hypothesis (Hasher \& Zacks, 1988) states that a fundamental mechanism underlying cognitive aging is the deterioration in inhibitory functions, which leads to a reduced ability to suppress the processing of task-irrelevant stimuli. On the basis of the idea of a pervasive factor affecting all stages of information processing, we predicted that betweengroup comparisons would reveal age-related decline in both early and late selection. Specifically, old participants would exhibit weaker early selection, as reflected by a reduction in the size of the SP and SN components, and reduced late selection, as reflected by a decline in the difference in the P3b amplitude between the attend and ignore conditions. We also anticipated that withinsubject comparisons would suggest that participants with evidence of the most robust early selection, as indexed by the size of the SP and SN, would generate the largest difference in P3b amplitude between conditions.

On the basis of the slowed processing speed theory of aging (Salthouse, 1996), we predicted that there would be age-related delays in indices of both early and late selection, as measured by the onset and peak latency of relevant ERPs. We hypothesized that age-associated delays in the execution of early selection would be 
associated with the delivery of suboptimal information upon which to carry out late selection. We anticipated that this processing deficiency would result in the increased appropriation of resources, as measured by P3b amplitude, in response to stimuli that were supposed to be ignored.

In terms of predictions about behavioral responses, it is important to note that task demands were purposely made easier for old participants to help minimize group differences in performance. This was done to allow us to draw inferences about age-related differences in neural activity and not performance-related differences. By making the task slightly easier for older participants, we expected that there would be no reliable differences in performance between young and old participant groups.

\section{METHODS}

\section{Participants}

Participants were recruited through community announcements in the Boston metropolitan area, including the Harvard Cooperative Study on Aging. All participants underwent informed consent approved by the Partners Human Research Committee and a detailed screening evaluation that included a structured interview to obtain a medical, neurological, and psychiatric history; a formal neurological examination; the completion of a neuropsychological test battery; and questionnaires surveying mood and socioeconomic status.

Young participants were between 19 and 29 years old, and old participants were between 67 and 80 years old. To be included in this study, participants had to be English-speaking, have $\geq 12$ years of education, have a Mini Mental State Exam (Folstein, Folstein, \& McHugh, 1975) score of $\geq 26$ and an estimated intelligence quotient (IQ) on the American National Adult Reading Test (AMNART; Ryan \& Paolo, 1992) of $\geq 100$. Participants were excluded if they had a history of CNS diseases or major psychiatric disorders based on DSM-IV criteria (American Psychiatric Association, 1994), focal abnormalities on neurological examination consistent with a CNS lesion, a history of clinically significant medical diseases, corrected visual acuity worse than 20/40 (as tested using a Snellen wall chart), a history of clinically significant audiological disease, a Beck Depression Inventory (Beck \& Steer, 1987) score of $\geq 10$ (for young participants) or a Geriatric Depression Scale (Yesavage et al., 1982) score of $\geq 10$ (for old participants), or were unable to distinguish between the color red and blue. Participants were paid for their time.

Although there is no universally accepted operational definition of executive functions, we followed the suggestion of many investigators who emphasize processes that include working memory, initiation, monitoring, and inhibition and advocate the use of at least several neuropsychological tests to assess this complex group of func- tions (Chan, Shum, Toulopoulou, \& Chen, 2008; Delis, Kaplan, \& Kramer, 2001; Spreen \& Strauss, 1998). We selected tests that had well-established norms across a wide range of ages. Tests of executive functions included (1) Digit Span Backward subtest of the WAIS-IV (Wechsler, 2008), which measures maintenance and manipulation operations of working memory; (2) Controlled Oral Word Association Test (Ivnik, Malec, Smith, Tangalos, \& Petersen, 1996), which indexes initiation, self-generation, and monitoring; (3) WAIS-IV Letter-Number Sequencing, which assesses maintenance, monitoring, and manipulation; (4) WAIS-IV Digit-Symbol Coding, which assesses sustained attention/persistence, cognitive speed, and efficiency; (5) Trail-Making Test Parts A and B (Reitan \& Wolfson, 1985), which measures planning/sequencing, set shifting, and inhibition.

Two groups of young adult participants and one group of old adult participants participated in the study. The executive capacity of young participants was matched to that of old participants using two methods. In the first method, young and old participants were matched based on age-appropriate norms. Participants in both age groups had high executive capacity, which was defined by a composite score in the top third ( $\geq 67$ th percentile). In the second method, young and old participants were matched based on young-adult norms. A review of performance using age-appropriate norms suggested that the raw scores of young participants with average capacity (33rd to 66th percentile) would be comparable to the raw scores of old adults with high capacity. Participant groups were labeled according to how they performed relative to age-appropriate norms (young-high executive capacity, young-average executive capacity, and old-high executive capacity). Additionally, pilot data suggested that despite matching for executive capacity, old participants still performed worse on the experimental task. To help minimize group differences in performance, task demands were made easier for old participants. Young participants responded to five target letters, and old participants responded to four target letters.

\section{Experimental Procedure}

The experiment consisted of a color-selective attention task in which participants were shown a series of letters presented in either the color red or the color blue on a white background and were asked to respond by button press to specific target letters. The number of target letters chosen for each age group was based on pilot data, with the aim of making behavioral performance comparable across groups. Young participants responded to five target letters, and old participants responded to four target letters. Participants were instructed to pay attention to letters appearing in the designated color while ignoring letters appearing in the other color and to respond by button press to target letters appearing in the designated color only. Participants were asked to respond as quickly and 
as accurately as possible to target letters. Practice trials preceded each set of experimental trials. The hand used for the target response was counterbalanced across participants, as was the attended color.

The task included 800 stimulus trials divided into eight blocks. Stimuli appeared one at a time within a fixation box that remained on the screen at all times and subtended a visual angle of $\sim 3.5^{\circ} \times 3.5^{\circ}$ at the center of a high-resolution computer monitor. Half of the stimuli appeared in color red and half in color blue, in randomized order. Target stimuli (7.5\% in attend color; $7.5 \%$ in ignore color) were five (for young) or four (for old) designated upper case letters. Standard stimuli (70\% overall; 35\% in each color) were any nontarget upper case letters. Novel visual stimuli accounted for the remainder of the stimuli presented. Visual stimuli subtended an angle of $2.5^{\circ}$ along their longest dimension and were presented for $250 \mathrm{msec}$. The ISI varied randomly between 815 and 1015 msec (mean 915 msec; see Figure 1). For analytic purposes, trials were further categorized in terms of whether the stimuli presented were in the attend or the ignore color. The attend condition consisted of all stimuli in the designated color; the ignore condition consisted of all stimuli in the nondesignated color.

\section{ERP Recordings}

An ActiveTwo electrode cap (Behavioral Brain Sciences Center, Birmingham, UK) was used to hold to the scalp a full array of $128 \mathrm{Ag}$-AgCl BioSemi (Amsterdam, The Netherlands) "active" electrodes whose locations were based on a preconfigured montage. Electrodes were arranged in equidistant concentric circles from the 1020 system position $\mathrm{Cz}$. In addition to the 128 electrodes on the scalp, six mini biopotential electrodes were placed over the left and right mastoid, beneath each eye, and next to the outer canthi of the eyes to check for eye blinks and vertical and horizontal eye movements. EEG activity was digitized at a sampling rate of $512 \mathrm{~Hz}$.

\section{Data Analysis}

Demographic variables and overall percentile performance on the neuropsychological tests for the three groups were compared using one-way ANOVAs. Target accuracy and mean RT were measured. A response was considered a hit if it occurred between 200 and $1000 \mathrm{msec}$ after stimulus presentation. Target stimuli correctly responded to (target hits) and stimuli incorrectly identified as targets (false alarms) were measured to determine an overall accuracy score (percent target hits - percent false alarms).

EEG data were analyzed using ERPLAB (www.erpinfo. org/erplab) and EEGLAB (Delorme \& Makeig, 2004; sccn.ucsd.edu/eeglab) tool boxes that operate within the MATLAB framework. Raw EEG data were resampled to $256 \mathrm{~Hz}$ and referenced off-line to the algebraic average of the right and left mastoids. EEG signals were filtered using an IIR filter with a bandwidth of 0.03-40 Hz (12 dB/ octave roll-off). Eye artifacts were removed through independent component analysis. Individual bad channels were corrected with the EEGLAB interpolation function. EEG epochs for the two stimulus types (standard and target) across two attention conditions (attend and ignore) were averaged separately. The sampling epoch for each trial lasted for $1200 \mathrm{msec}$, including a 200-msec prestimulus period that was used to baseline correct the ERP epochs. Trials were discarded from the analyses if they contained baseline drift or movement artifacts greater than $90 \mu \mathrm{V}$.

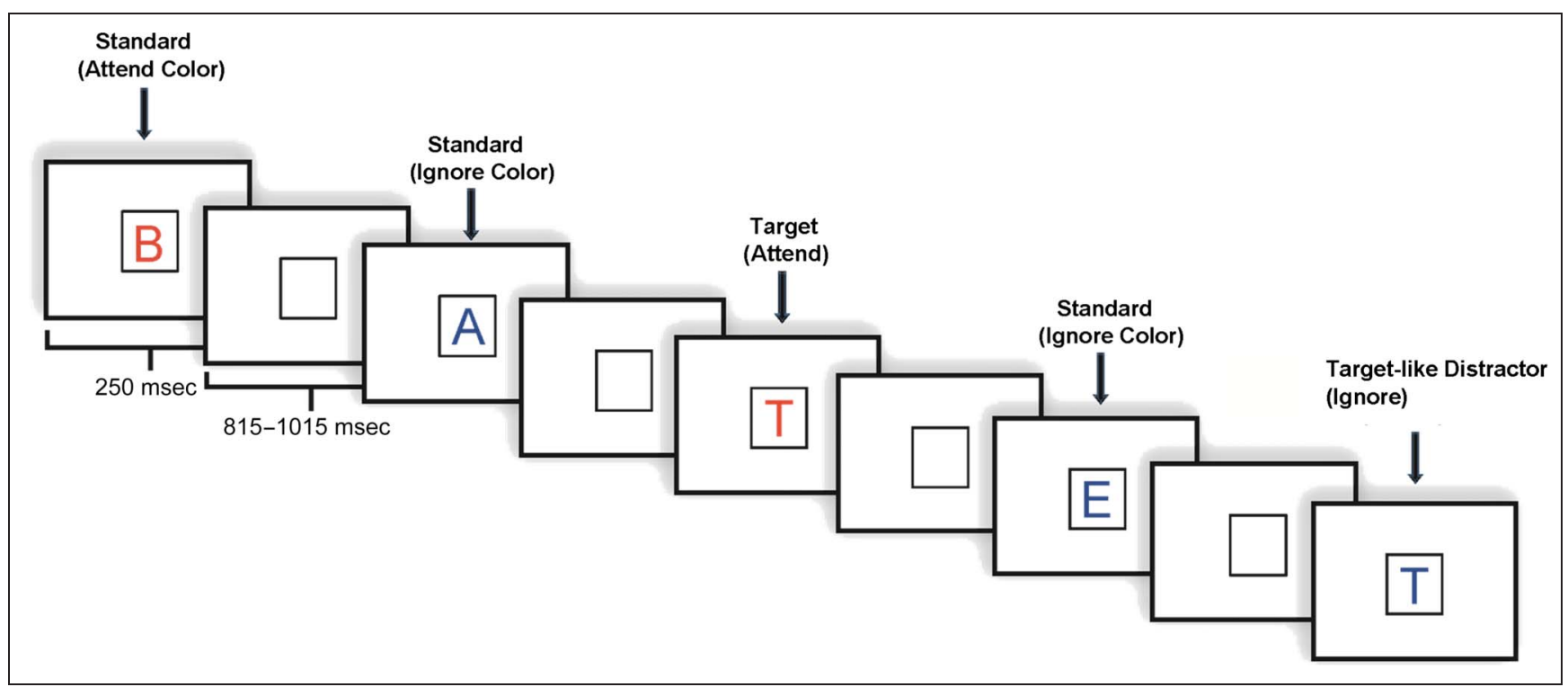

Figure 1. Illustration of an experimental run. 
Figure 2. Montage illustrating the location of 128 electrode sites and the 10 designated ROIs.

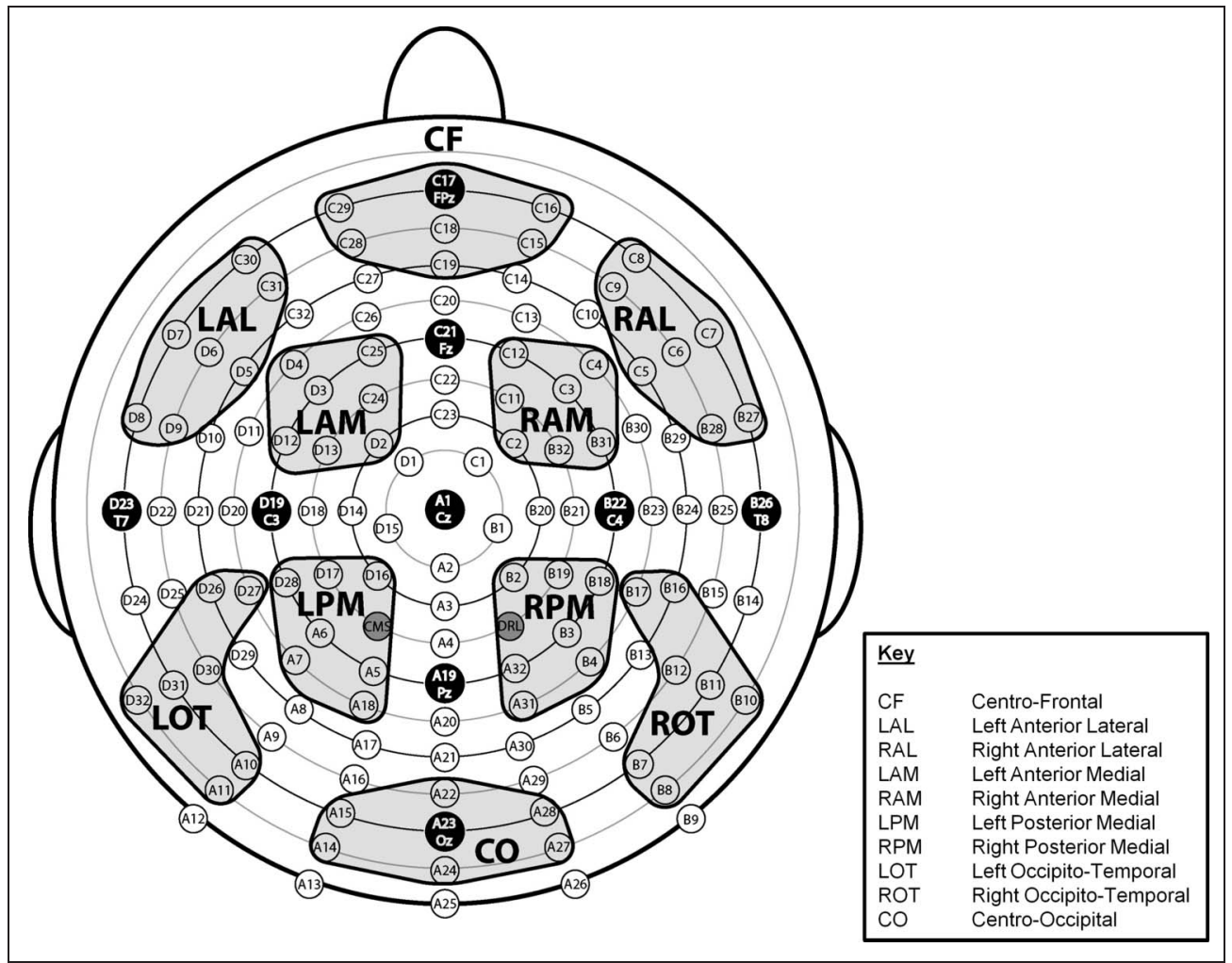

Only trials with correct responses were included in the analyses.

ROIs across the scalp were designated and labeled centrofrontal (CF), left anterior lateral (LAL), right anterior lateral (RAL), left anterior medial (LAM), right anterior medial (RAM), left posterior medial (LPM), right posterior medial (RPM), left occipito-temporal (LOT), right occipito-temporal (ROT), and centro-occipital (CO; see Figure 2). Each region reflected a cluster of seven electrode sites.

Consistent with reports in the literature (McGinnis \& Keil, 2011; Muller \& Keil, 2004; van der Stelt, Kok, Smulders, Snel, \& Boudewijn Gunning, 1998), for ERP measures of early selection (SP and SN), the analysis focused on responses to standard stimuli. For the ERP measure of late selection (P3b), the analysis focused on responses to target and not standard letters, the stimulus type for which the P3b component is most commonly measured (Lorenzo-Lopez, Amenedo, Pazo-Alvarez, \& Cadaveira, 2007; Muller \& Keil, 2004; van der Stelt et al., 1998). The latency of the SP was measured as the local positive peak latency for the attend-ignore (A-I) difference wave between 100 and $275 \mathrm{msec}$ in response to standard stimuli at anterior ROIs (CF, LAL, RAL, LAM, RAM). The latency of the $\mathrm{SN}$ was measured as the local negative peak latency for the A-I difference wave between 200 and $350 \mathrm{msec}$ in response to standard stimuli at posterior ROIs (LPM, RPM, LOT, ROT, CO). SP and SN latencies were measured using A-I difference waves to ensure we were capturing the peak difference between conditions. The latency of the P3b was measured as the local positive peak latency under the attend ${ }^{1}$ condition between 400 and $700 \mathrm{msec}$ in response to target stimuli at the midline electrode site Pz. ERP latencies for SP and SN were analyzed using repeated-measures ANOVA, with ROI as a withinsubject variable and Age as the between-subject variable. ERP latency for the P3b was analyzed using a one-way ANOVA. Because of concerns about the potential impact of high-frequency noise on peak latency values (Luck, 2005), processing speed was also assessed using timecourse analyses. For the SP and SN, repeated-measures ANOVAs were performed separately on the young and old groups to determine the temporal intervals in which mean values showed a reliable difference between attend and ignore conditions. For the P3b component, onesample $t$ tests were carried out to determine the temporal intervals in which mean values under the attend condition differ significantly from $0 \mu \mathrm{V}^{2}$. Details of the specific temporal epochs investigated are provided in the text.

The size of the SP, SN, and P3b was derived from the mean amplitude of the 100-msec interval centered at the mean local peak latency for each component. The mean amplitudes of the SP, SN, and P3b were analyzed using repeated-measures ANOVA with Condition (attend and ignore) and ROI as within-subject variables, and Age Group as the between-subject variable. Analyses that yielded significant interactions between age group and condition or ROI resulted in planned contrasts between levels of the variable. The Greenhouse-Geisser correction was applied for all repeated-measures with greater than 1 degree of freedom. Simple linear regression analyses were 
Table 1. Participant Characteristics, Mean (SD)

\begin{tabular}{lccr}
\hline Variable & Young-high & Young-average & Old \\
\hline Number of participants & 13 & 13 & 17 \\
Sex (male:female) & $5: 8$ & $7: 6$ & $7: 10$ \\
Age** & $22.54(1.66)$ & $22.62(2.72)$ & $74.65(3.98)$ \\
EC percentile: age-matched norms** & $80.71(8.20)$ & $54.05(11.46)$ & $51.80(7.26)$ \\
EC percentile: young adult norms*** & $80.71(8.20)$ & $54.05(11.46)$ & $52.43(7.04)$ \\
Years of education & $15.88(1.58)$ & $14.42(1.13)$ & $16.53(3.50)$ \\
AMNART* & $119.15(4.63)$ & $114.31(7.67)$ & $122.06(8.40)$ \\
\hline
\end{tabular}

$\mathrm{EC}=$ executive capacity.

*Effect of group, $p<.05$.

**Effect of group, $p<.001$.

run to explore the relationship between ERP indices of early and late selection.

\section{RESULTS}

\section{Participants}

See Table 1 for participant characteristics, including demographic information, neuropsychological test performance, and estimated IQ for each age group, as well as pertinent statistical analyses. Forty-three participants participated in this study: 13 young participants with high executive capacity, 13 young participants with average executive capacity, and 17 old participants with high executive capacity. High and average executive capacity was defined based on performance relative to published agematched norms. An additional two young-high capacity, one young-average capacity, and three old-high capacity participants were excluded because of excessively noisy data. When using age-appropriate norms for the tests of executive function, the groups differed in their overall percentile performance, $F(2,40)=41.91, p<.001$. As anticipated, young-average participants had a lower percentile score than young-high participants and old-high participants, with no difference between the latter two groups (young-average $<$ young-high, $p<.001$; youngaverage $<$ old-high, $p<.001$; young-high $=$ old-high, $p>$.74). When applying young-adult norms to all three groups, there also was an effect of group, $F(2,40)=$ $43.55, p<.001$, but the pattern was quite different. Young-high participants had a higher percentile score than young-average and old-high groups, with no differ- ence between the latter two groups (young-high $>$ young-average, $p<.001$; young-high $>$ old-high, $p<$ .001 ; young-average $=$ old-high, $p>$.63). The three groups differed in their estimated IQ according to AMNART (Ryan \& Paolo, 1992), $F(2,40)=4.25, p=.02$, such that young-average participants had a lower estimated IQ than old-high participants (young-average < old-high, $p<.01$; young-average $=$ young-high, $p>$ .09 ; old-high $=$ young-high,$p>.28$ ). The groups did not differ in number of years of education.

\section{Behavior}

The results of target accuracy and mean RT are presented in Table 2. Note that task demands were made easier for old participants (four target letters) than young participants (five target letters). In terms of accuracy, there was an effect of Group, $F(2,39)=6.75, p=.003$, with young-average participants having lower scores than either young-high or old-high participants, with no difference between the latter two groups (young-average $<$ young-high, $p<.01$; young-average $<$ old-high, $p<$ .005 ; young-high $=$ old-high, $p>.64$ ). There were no group differences in mean RT.

\section{ERPs}

This article focused on the impact of aging on ERP markers of early and late selection. Main effects or interactions that did not include the factor of Age Group as well as nonsignificant results are not presented, unless of particular

Table 2. Accuracy and Mean RT, Mean $(S D)$

\begin{tabular}{lccc}
\hline Behavioral Variable & Young-high & Young-average & Old \\
\hline Accuracy $(\%)^{*}$ & $91.73(7.32)$ & $85.03(6.22)$ & $92.79(4.73)$ \\
Mean RT $(\mathrm{msec})$ & $591(40)$ & $628(57)$ & $631(55)$ \\
\hline
\end{tabular}

*Effect of group, $p<.01$. 
Figure 3. Grand-averaged ERP responses under attend and ignore conditions at all $10 \mathrm{ROIs}$ in response to standard stimuli for young-high, young-average, and old-high participants.

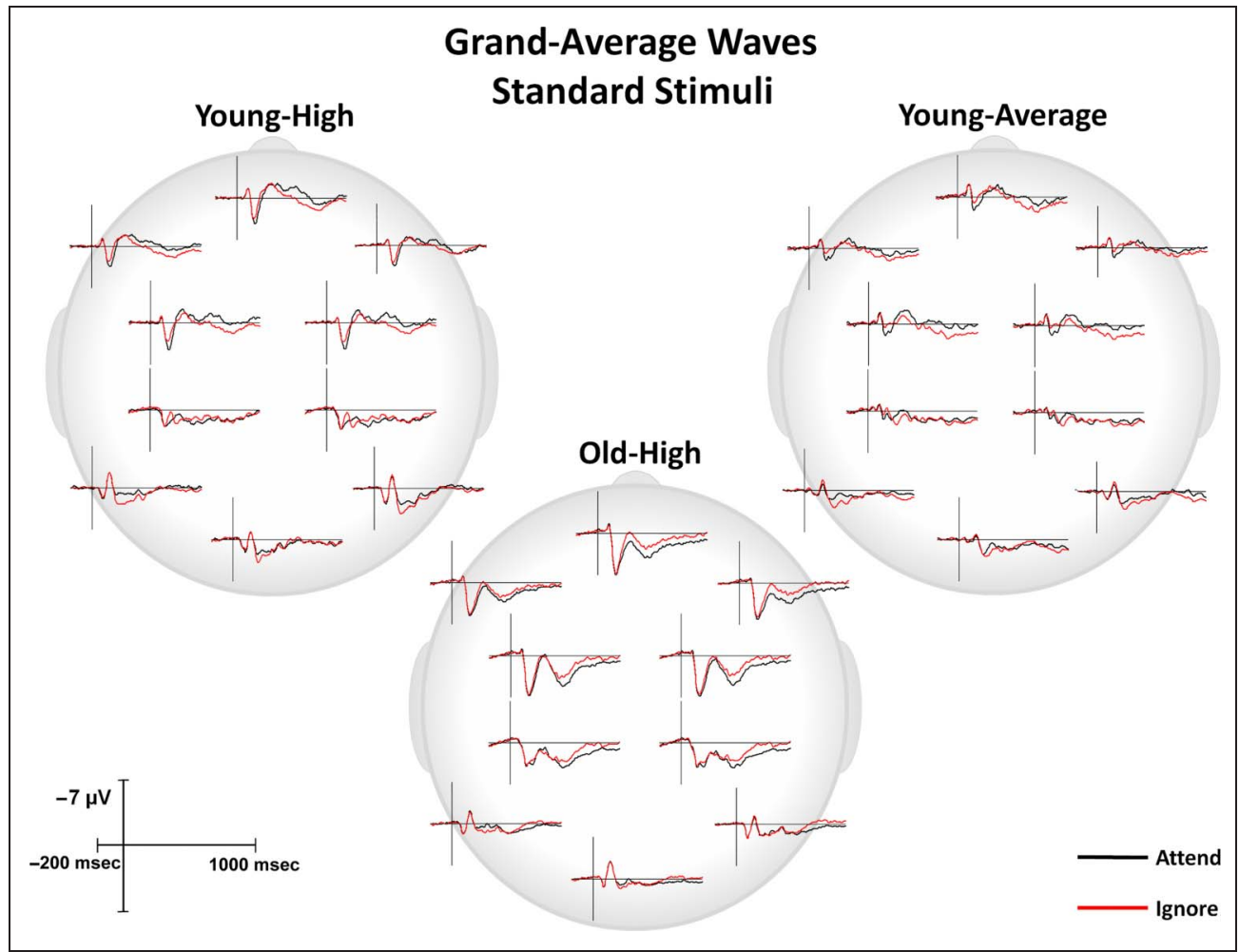

theoretical interest. The grand-averaged ERP responses for young and old participants to standard stimuli and target stimuli under the attend and ignore conditions at all 10 ROIs are presented in Figures 3 and 4, respectively. Representative ROIs are featured in subsequent figures, as described below.

Figure 4. Grand-averaged ERP responses under attend and ignore conditions at all 10 ROIs in response to target stimuli for young-high, young-average, and old-high participants.

\section{Selection Positivity (SP)}

Figure 5 illustrates the grand-averaged ERPs at anterior ROIs (CF, LAL, RAL, LAM, RAM) in response to standard stimuli. Figure $6 \mathrm{~A}$ depicts the voltage difference maps of the attend-ignore difference waves during the temporal

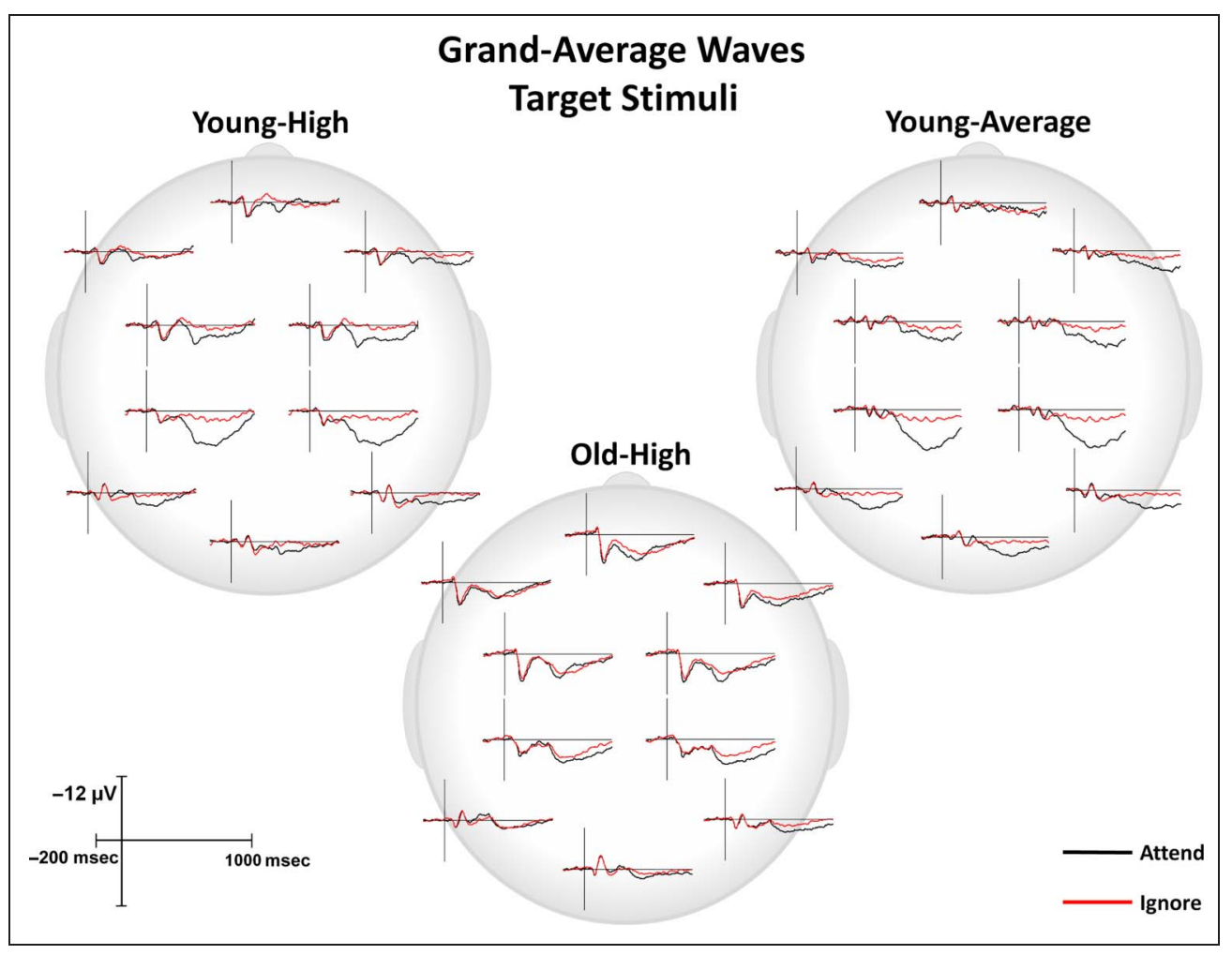


Figure 5. Illustration of the grand-averaged ERP responses under attend and ignore at the anterior ROIs in response to standard stimuli. The highlighted area represents the temporal interval in which the SP was measured.

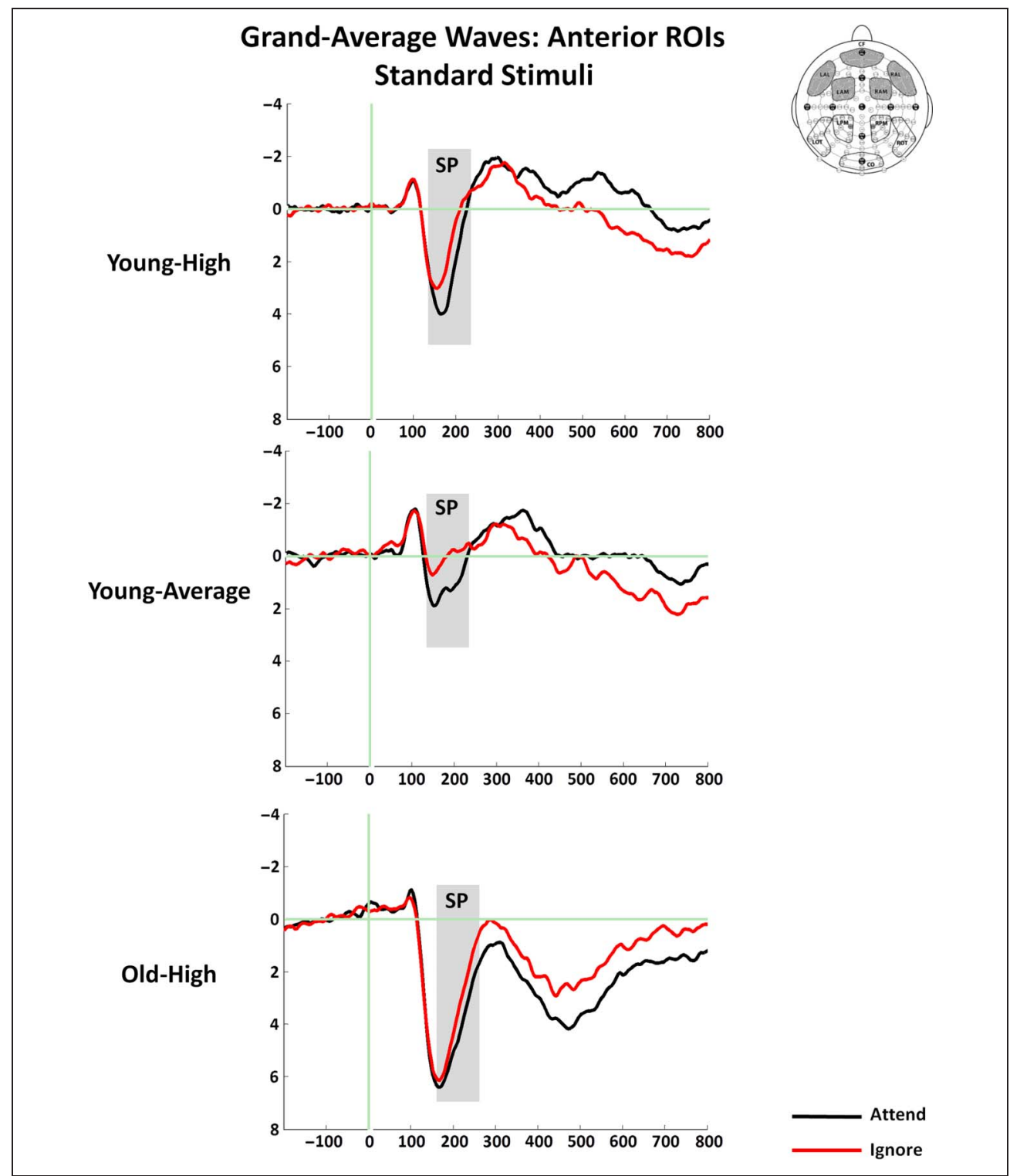

interval of the SP. An ANOVA for the SP latency was noteworthy for an effect of age group, $F(2,40)=4.92$, $p=.01$, which was present because the mean latency of the old-high participants $(M=211 \mathrm{msec}, S D=33 \mathrm{msec})$ was later than that of young-high $(M=191 \mathrm{msec}, S D=$ $10 \mathrm{msec}$ ) and young-average $(M=182, S D=26 \mathrm{msec})$ participants, with no difference between the latter two groups (old-high $>$ young-high, $p<.05$; old-high $>$ young-average, $p<.01$; young-high $=$ young-average $p>$.36). Time-course analysis using repeated-measures ANOVA (A vs. I) performed on $25 \mathrm{msec}$ epochs between 150 and 250 msec in response to standard stimuli demonstrated that the onset of the SP was $\sim 50-75$ msec earlier for both groups of young participants than old participants (Table 3).

The amplitude of the SP was measured as the mean value of 135-235 msec for young-high and young-average participants and 160-260 msec for old participants at the five anterior ROIs (CF, LAL, RAL, LAM, RAM). A 3 (Age Group) $\times 2$ (Condition) $\times 5$ (ROI) ANOVA was noteworthy for an effect of Condition, $F(2,40)=37.04, p<.001$, which was because of the mean amplitude being larger under the attend condition than the ignore condition. ${ }^{3}$ Of particular relevance to the goals of this study, the magnitude of the difference between attend and ignore was not different for young and old participants (No Condition $\times$ Age Group interaction: $F(2,40)=0.34, p=.72){ }^{4}$

\section{Selection Negativity (SN)}

Figure 7 illustrates the grand-averaged ERPs at ROI LOT in response to standard stimuli. Figure $6 \mathrm{~B}$ depicts voltage difference maps of the attend-ignore difference waves during the temporal interval of the SN. An ANOVA for the SN latency revealed an effect of Age, $F(2,40)=$ $3.15, p=.05$, such that the latency of the old-high 
participants $(M=294 \mathrm{msec}, S D=35 \mathrm{msec})$ was later than that of the young-high participants $(M=265 \mathrm{msec}$, $S D=32 \mathrm{msec}$ ) and the latency of the young-average participants $(M=281 \mathrm{msec}, S D=25 \mathrm{msec})$ was not different from either group (old-high $>$ young-high, $p<.05$; old-high $=$ young-average, $p>.24$; younghigh $=$ young-average, $p>.22$ ). However, time-course analysis using repeated-measures ANOVA (A vs. I) performed on 25 msec epochs between 200 and 350 msec in response to standard stimuli demonstrated that the onset of the SN was $\sim 50-75 \mathrm{msec}$ earlier for both groups of young participants compared with old participants (Table 3).

The amplitude of the SN was measured as the mean value of 215-315 msec for young-high participants, 230-330 msec for young-average participants, and 245$345 \mathrm{msec}$ for old-high participants at the five posterior ROIs (LPM, RPM, LOT, ROT, CO). A 3 (Age group) $\times 2$ (Condition $) \times 5(\mathrm{ROI})$ ANOVA revealed a robust interaction between Condition and ROI, $F(4,160)=6.63, p<.001$. The interaction between Condition and ROI was explained by the largest difference between conditions being found at lateral posterior sites, especially on the left (i.e., LOT), which became the focus of further analyses. Of note, the eta-squared for the condition effect was over twice as large at ROI LOT than at any other ROI. At ROI LOT, an ANOVA revealed an effect of Condition, $F(1,40)=$ $45.48, p<.001$, which was because of more negative-going ERPs under the attend than the ignore condition. Additionally, the magnitude of the difference between attend and ignore was not different for young and old participants $($ No Condition $\times$ Age Group interaction; $F(2,40)=1.51$, $p=.23){ }^{4}$

\section{P3b}

Figure 8 illustrates the grand-averaged ERPs at ROIs LPM and RPM in response to target stimuli. Figure $6 \mathrm{C}$ depicts the voltage difference maps of the attend-ignore difference waves during the temporal interval of the P3b. A one-way ANOVA for the P3b latency showed a difference between groups, $F(2,40)=5.71, p=.007$, revealing that the local peak latency of the young-average $(M=$ $639 \mathrm{msec}, S D=51 \mathrm{msec}$ ) was later than the peak latency of the young-high $(M=540, S D=93 \mathrm{msec})$ and old-high ( $M=583, S D=75 \mathrm{msec}$ ) groups, with no difference between the latter two groups (young-average $>$ younghigh, $p<.005$; young-average $>$ old-high, $p<.05$; oldhigh $=$ young-high, $p>$.13). ${ }^{5}$ Time-course analysis was conducted using one-sample $t$ tests performed on $25 \mathrm{msec}$ epochs between 350 and $500 \mathrm{msec}$ in response to target stimuli under the attend condition. This analysis
Figure 6. Voltage difference maps of the attend-ignore difference waves for the (A) SP to standard stimuli, (B) SN to standard stimuli, and (C) P3b component to target stimuli. Note that the scale for $\mathrm{A}$ and $\mathrm{B}$ is -2 to $2 \mu \mathrm{V}$ and the scale for $\mathrm{C}$ is -2 to $8 \mu \mathrm{V}$.

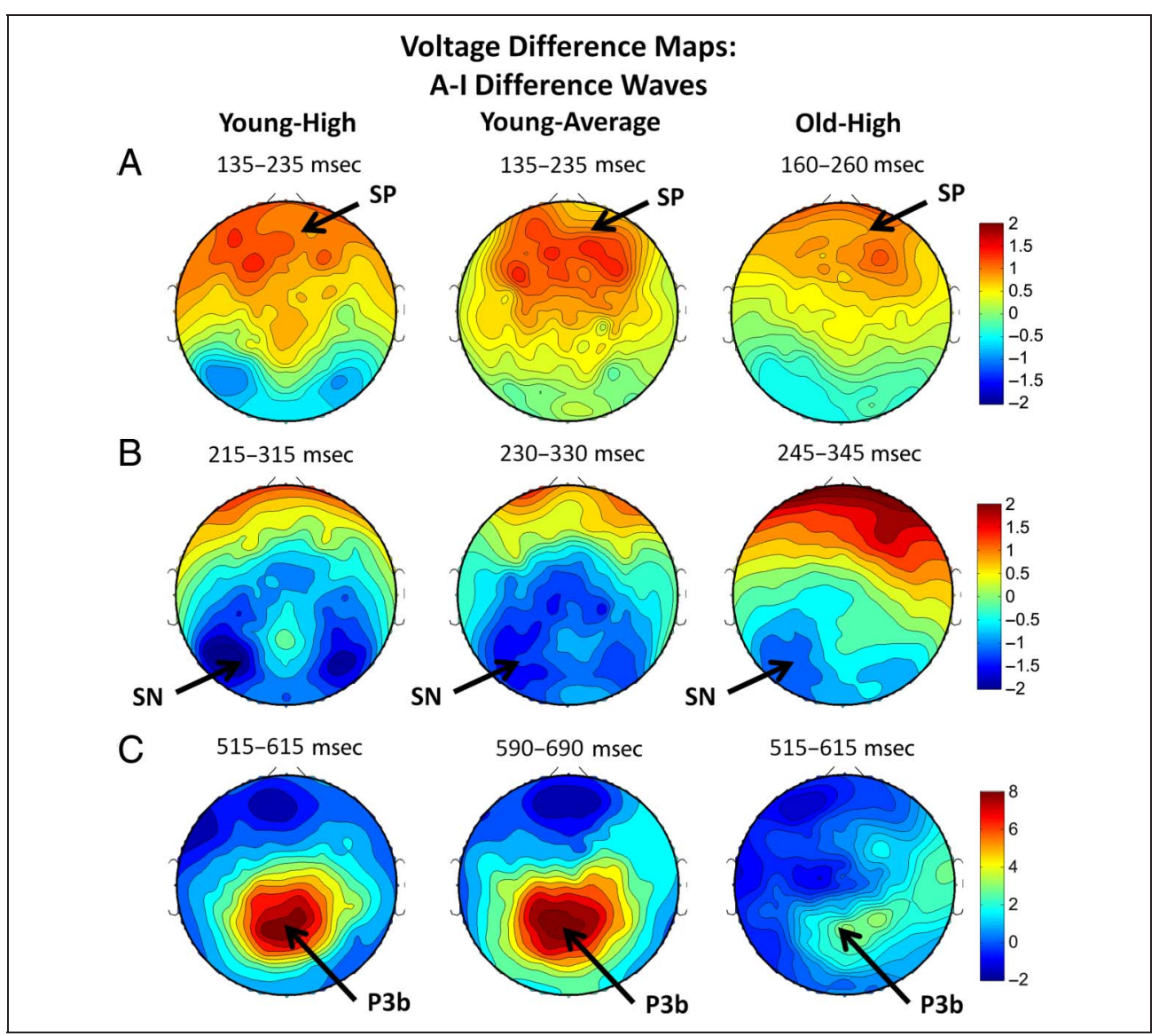


Table 3. Time-course Analysis in Response to Standard Stimuli for SP and SN and in Response to Target Stimuli for the P3b

\begin{tabular}{|c|c|c|c|c|c|c|c|c|}
\hline \multirow[b]{2}{*}{ Component } & \multirow[b]{2}{*}{ Condition } & \multirow[b]{2}{*}{ Group } & \multicolumn{5}{|c|}{ Interval } & \\
\hline & & & $125-150$ & $150-175$ & $175-200$ & $200-225$ & $225-250$ & \\
\hline \multirow[t]{4}{*}{$\mathrm{SP}^{\mathrm{a}}$} & A vs. I & Young-high & & $<.01$ & $<.01$ & $<.01$ & & \\
\hline & & Young-average & $<.05$ & $<.05$ & $<.01$ & $<.05$ & & \\
\hline & & Old-high & & & & $<.01$ & $<.01$ & \\
\hline & & & $200-225$ & $225-250$ & $250-275$ & $275-300$ & $300-325$ & $325-350$ \\
\hline \multirow[t]{4}{*}{$\mathrm{SN}^{\mathrm{b}}$} & A vs. I & Young-high & $<.05$ & $<.01$ & $<.01$ & $<.01$ & $<.05$ & \\
\hline & & Young-average & & $=.05$ & $<.01$ & $<.01$ & $<.05$ & $<.05$ \\
\hline & & Old-high & & & & $<.05$ & $<.01$ & $<.05$ \\
\hline & & & $350-375$ & $375-400$ & $400-425$ & $425-450$ & $450-475$ & $475-500$ \\
\hline \multirow[t]{3}{*}{$\mathrm{P} 3 \mathrm{~b}^{\mathrm{c}}$} & $\mathrm{A}$ & Young-high & $<.01$ & $<.01$ & $<.01$ & $<.01$ & $<.01$ & $<.01$ \\
\hline & & Young-average & & $<.05$ & $<.01$ & $<.01$ & $<.01$ & $<.01$ \\
\hline & & Old-high & & & & & $<.05$ & $<.05$ \\
\hline
\end{tabular}

Repeated-measures ANOVA ( $p$ values) between conditions for the SP and SN by 25 msec epochs and one-sample $t$ test ( $p$ values) for the P3b by 25 msec epochs.

$\mathrm{A}=$ attend condition; $\mathrm{I}=$ ignore condition.

${ }^{a}$ Measured at anterior ROIs (CF, LAL, RAL, LAM, RAM).

${ }^{\mathrm{b}}$ Measured at ROI LOT.

${ }^{\mathrm{c}}$ Measured at ROIs LPM and RPM.

demonstrated a different pattern from that found using peak latency analysis such that the onset of the P3b was $\sim 100-125$ msec earlier for young participants than old participants (see Table 3).

On the basis of the P3b literature, we anticipated that the P3b would be largest at centro-posterior ROIs LPM and RPM. To confirm this, the amplitude of the P3b in response to target stimuli was measured as the mean value between 515 and $615 \mathrm{msec}$ for the young-high and old-high groups and 590-690 msec for the young-average group at all five posterior ROIs (LPM, RPM, LOT, ROT, CO). A 3 (Age group) $\times 2$ (Condition) $\times 5$ (ROI) ANOVA revealed a robust effect of ROI, $F(4,160)=79.05, p<$ .001 , and an interaction between ROI and Condition, $F(4$, $160)=30.47, p<.001$. The ROI effect was because of the amplitude of the P3b being larger at ROIs LPM and RPM than all other ROIs. The ROI $\times$ Condition effect was present because the largest condition effects were found at ROIs LPM and RPM. Because of these effects, ROIs LPM and RPM became the focus of further analysis. Of note, the eta-squared for the condition effect was 50\% larger for ROIs LPM and RPM than it was for any of the other ROIs. At ROIs LPM and RPM, an ANOVA revealed an interaction between Condition and Age Group, $F(2$, $40)=6.85, p=.003$. This interaction was because of the difference between attend and ignore being much smaller for the old group than the young-high group (Age Group $\times$ Condition interaction: $F(1,28)=12.27, p=.002)$ and the young-average group (Age Group $\times$ Condition interaction: $F(1,28)=6.34, p=.02$ ), with no difference between the two young groups, $F(1,24)=.54, p=.47$. Additionally, there was a reliable difference between the attend and ignore conditions for the young-high group (condition effect: $F(1,12)=63.08, p<.001)$ and the young-average group (condition effect: $F(1,12)=25.13, p<.001$ ), but no significant difference between conditions for the old group (condition effect: $F(1,16)=2.73, p=.12$ ). ${ }^{6}$

\section{Regression Analyses}

We hypothesized that the size/latency of early selection (SP and SN) would predict the size/latency of late selection (P3b). To test this prediction, simple linear regression analyses were run. We found no relationships between SP or SN peak latency or amplitude and P3b latency or amplitude. As an exploratory analysis, we tested whether the timing (earlier onset) of early selection had an impact on the magnitude of late selection. Regression analyses were run between the amplitude of the SP and SN during the early intervals measured for the time course analysis 
Figure 7. Illustration of the grand-averaged ERP responses under attend and ignore at ROI LOT in response to standard stimuli. The highlighted area represents the temporal interval in which the $\mathrm{SN}$ was measured.

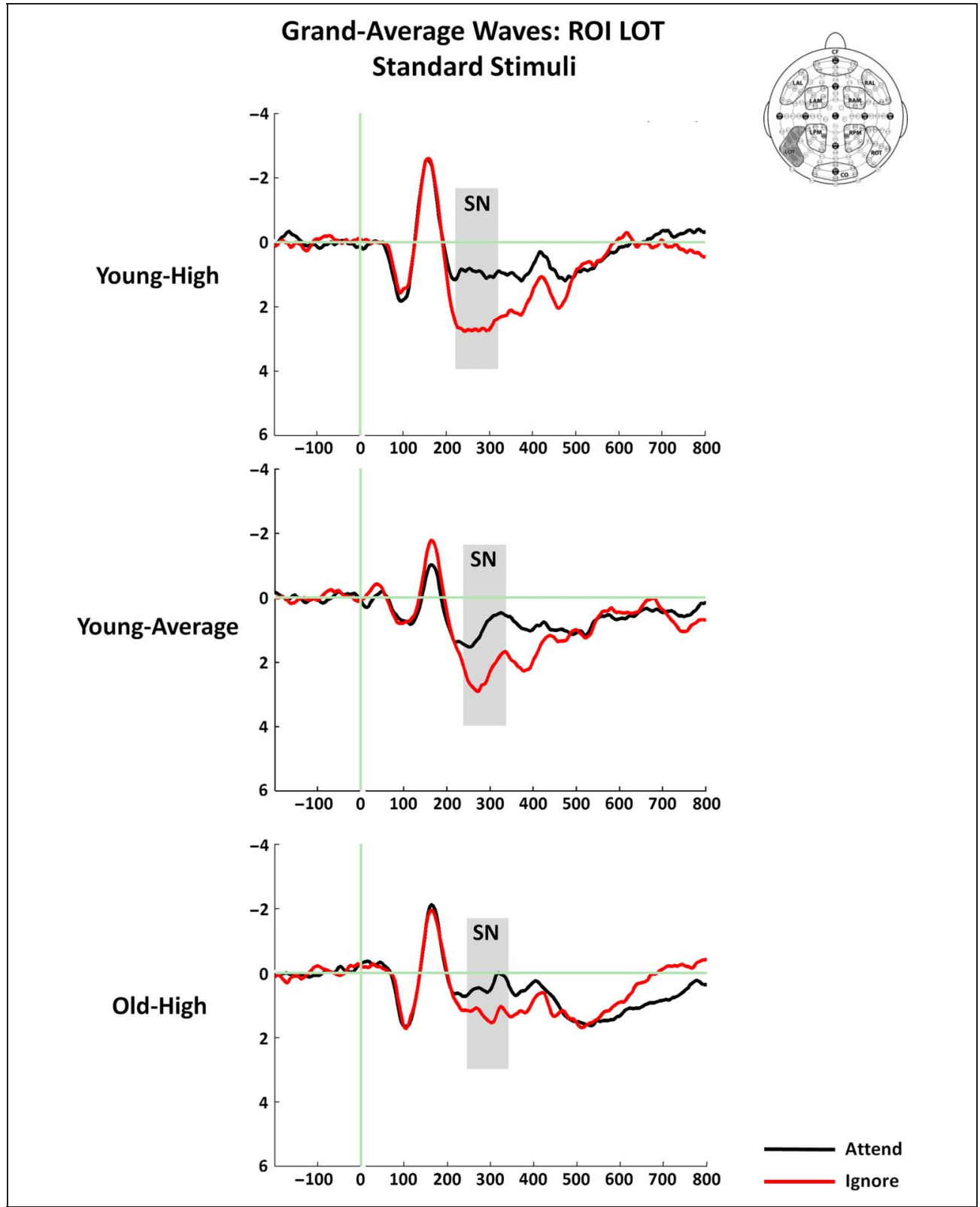

and the difference in $\mathrm{P} 3 \mathrm{~b}$ amplitude between the attend and ignore conditions. The only intervals included were those in which both groups of young participants exhibited an SP or SN whereas old participants did not (150-175 msec, 175-200 msec, 150-200 msec for the SP; 225-250 msec, 250-275 msec, and 225-275 msec for the $\mathrm{SN}$; see Table 3). We found that the magnitude of the difference between attend and ignore for the SP at the 150-175 msec, 175-200 $\mathrm{msec}$, or the 150-200 msec epoch predicted the magnitude of the difference between attend and ignore for the P3b: The smaller the difference between attend and ignore for the SP, the smaller the difference between attend and ignore for the P3b $[r(41)=$ $.45, p=.003 ; r(41)=.36, p=.02 ;$ and $r(41)=.44$, $p=.003$, respectively]. The $150-175 \mathrm{msec}$ and the 150 $200 \mathrm{msec}$ intervals survived controlling for age $[r(40)=$
$.36, p=.02$ and $r(40)=.33, p=.03]$ whereas the $175-200$ msec interval did not $[r(40)=.24, p=.13] .^{7}$

\section{DISCUSSION}

There is considerable evidence that older adults exhibit a reduced ability to limit the processing of task-irrelevant stimuli (Gazzaley et al., 2005, 2008; Milham et al., 2002; McDowd \& Filion, 1992). However, it remains to be determined where along the information processing stream the most salient age-related changes occur. The main purpose of this study was to use the high temporal resolution of ERPs to examine the extent to which these differences reflect changes in early selection, late selection, or both. 
We aimed to match old and young participants in terms of executive function because of strong evidence for its role in mediating selective attention (Rutman, Clapp, Chadick, \& Gazzaley, 2010; Lavie, Hirst, de Fockert, \& Viding, 2004; Desimone \& Duncan, 1995). We achieved our goal of having old participants matched to one group of young participants based on age-appropriate norms for neuropsychological tests of executive functions and to another group of young participants based on non-age-adjusted norms. We were partially successful in matching groups for performance on the experimental paradigm. Making the task easier for high-capacity old participants may have allowed them to be as accurate as high-capacity young participants but probably contributed to their being more accurate than average-capacity young participants.
For the amplitude of the anterior SP and posterior $\mathrm{SN}$, our results indicate that there were no differences between the old group and either young group. Thus, in the current task, age seemed to have a limited effect on the magnitude of overall modulation of early selective attention. However, older participants carried out early selective attention operations at a slower rate, as measured by delays in the onset of the SP and SN components. During late selection, both groups of young participants generated a highly differentiated $\mathrm{P} 3 \mathrm{~b}$ response to target letters that were supposed to be attended compared with those that were supposed to be ignored based on color. In striking contrast, the old group generated a large P3b to target letters under both the attend and ignore conditions, with no reliable differences in amplitude between the two conditions. Thus, old adults
Figure 8. Illustration of the grand-averaged ERP responses under attend and ignore at ROIs LPM and RPM in response to target stimuli. The highlighted area represents the temporal interval in which the $\mathrm{P} 3 \mathrm{~b}$ was measured.

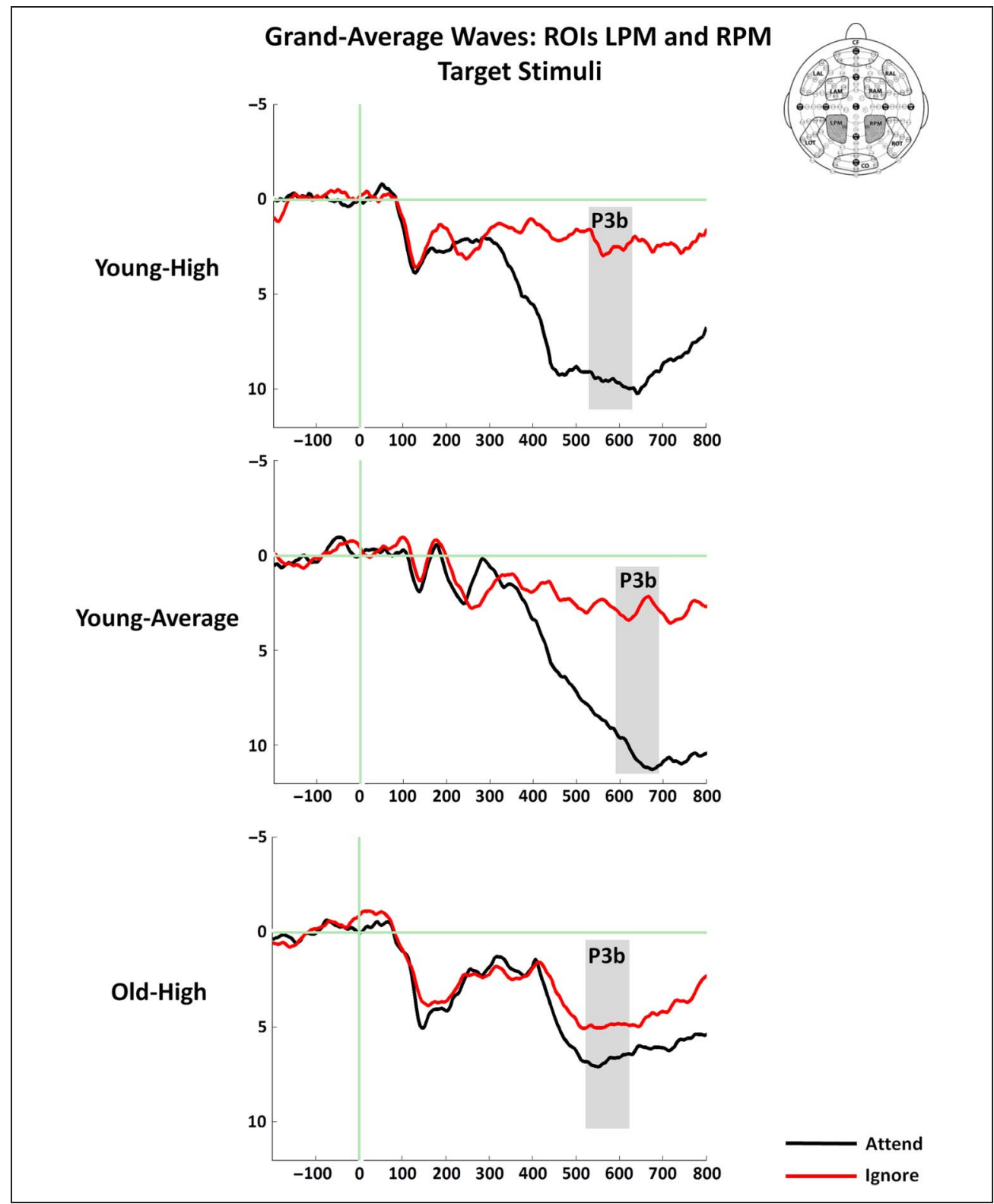


demonstrated a dissociation involving the preservation of a well-differentiated neural response between attend and ignore conditions during early selection, but not late selection. Our results also indicate there were age-related delays not only in early selection (filtering), as indexed by the onset of the SP and SN, but also late selection (decision-making), as measured by the onset of the P3b.

Theoretically, if early in the processing stream participants can delineate which stimuli should be ignored based on an elementary physical property like color, one would expect them to be able to limit the resources allocated to such stimuli during later decision-making operations. However, older participants do not appear to successfully accomplish this task. Despite seemingly adequate early selective attention in which to-be-ignored stimuli are treated differently from to-be-attended stimuli, older participants fail to continue to generate a highly differentiated neural response during subsequent processing. Compared with their younger counterparts, they appropriate excessive resources for stimuli that are supposed to be ignored. By matching the executive capacity of our old participant group to young participants in two ways, we were able to strengthen our argument that the age-related differences found in this study are a result of aging rather than differences in executive function.

Several theories of cognitive aging offer accounts for why older participants exhibit excessive processing under the ignore condition. For example, according to the inhibitory deficit hypothesis, a fundamental feature of cognitive aging is an overall decline in inhibitory functions that leads to the reduced ability to suppress the processing of stimuli that are supposed to be ignored (Hasher \& Zacks, 1988). Allocation of excessive resources to task-irrelevant stimuli can also be framed in terms of the dedifferentiation hypothesis of aging (Ghisletta \& de Ribaupierre, 2005; Li \& Lindenberger, 1999; Baltes \& Lindenberger, 1997), which stresses an age-related failure to recruit specialized neural mechanisms and generate differentiated responses to various classes of stimuli, in this case to-be-attended versus to-be-ignored events. Because these theories propose the existence of a central mediating factor that has a widespread impact on all facets of information processing, they cannot provide a ready explanation for our finding of an age-related dissociation between early and late selection.

Our results are consistent with research showing that inhibitory deficits and dedifferentiation associated with aging are not ubiquitous but may vary across specific cognitive operations (Anguera \& Gazzaley, 2012; Gazzaley et al., 2008; Voss et al., 2008; Kramer, Humphrey, Larish, Logan, \& Strayer, 1994). For example, in a study of cognitive aging, Anguera and Gazzaley (2012) found no correlations between ERP markers of sensory suppression and motor inhibition. Also consistent with our findings are studies reporting that older adults generate a less differentiated $\mathrm{P} 3 \mathrm{~b}$ response to stimuli that vary in task relevance or salience (Hahn et al., 2011; Curran, Hills,
Patterson, \& Strauss, 2001; Kenemans et al., 1995; Looren de Jong et al., 1988). ${ }^{8}$

Several explanations may contribute to our understanding of the dissociation between early and late selection in older participants. A particularly appealing idea is that aging leads to a discontinuity or delay of information flow that keeps the output of early processing from readily becoming the input of later processing. In support of this, the current study found age-related slowing in processing speed that may negatively impact the outcome of cognitive operations (Salthouse, 1996). For example, age-associated delays in early selection, as indexed by prolonged SP and SN onset, may mean that subsequent decision-making operations, as indexed by the P3b, need to be carried out using suboptimal information. Alternatively, because of slowed processing speed, the products of early selection may decay by the time later selection needs to be completed. Degradation in the ability to hold relevant information on-line may lead to the reprocessing of data or the repetition of critical operations (Salthouse, 1996). The results of our exploratory analyses lend support for the central role of slowed processing speed in the age-associated differences on this task. The size of the SP at the earliest temporal intervals of the time-course analysis predicted the magnitude of the difference between attend and ignore for the P3b, even after controlling for age. This relationship suggests that individuals who are slow to initiate early selection are less successful generating differentiated responses during late selection. To the best of our knowledge, this is the first report directly linking delays in the onset of ERP components indexing early operations to an alteration in the size of the ERP response indexing later operations.

Although relative to their younger counterparts, old adults appear to appropriate excessive resources to taskirrelevant stimuli during later processing stages, it remains to be determined if this represents an adaptive mechanism that allows them to achieve cognitive goals in the context of declining function during earlier stages (Park \& Reuter-Lorenz, 2009; Davis, Dennis, Daselaar, Fleck, \& Cabeza, 2008). It is important to note that all of the old participants in this study had high executive capacity and did reasonably well on the experimental task. Interpretation of the functional significance of their neural responses will be aided by future research that includes older participants with average executive capacity or those who perform less well on the task. Finding that high-performing old participants generate a larger P3b than average-performing old participants in response to target-like stimuli under the ignore condition would support the notion that the enhanced P3b observed here may represent compensatory activity. Alternatively, finding that low- or average-performing old participants generate a larger P3b than high-performing old participants would lead to the conclusion that an enhanced $\mathrm{P} 3 \mathrm{~b}$ in response to to-be-ignored stimuli may not represent compensatory activity, but rather an age-related deterioration of late 
controlled processing (Daffner, Sun, et al., 2011; Riis et al., 2008).

Another explanation of the dissociation between early and late selection is that the young and old adults carry out the task differently. Young participants may follow the processing model outlined in the Introduction, initially filtering stimuli on the basis of a simple physical characteristic, color, as indexed by the SP and SN components (Daffner, Tarbi, et al., 2012; Daffner, Zhuravleva, et al., 2012). They then focus on the stimuli selected by this readily identifiable feature to discriminate among letter forms and identify designated targets, a process indexed by the P3b component. In contrast, older adults may approach the task by first identifying which letter forms are targets and then select only the ones that are in the designated color. Late selection resources, as indexed by the P3b, would be allocated to all target letter forms as part of the process of determining whether they are in the appropriate target color. If this were the case, it would suggest that older adults spontaneously adopt a less efficient strategy and may waste processing resources. In this scenario, older adults must closely attend to twice the number of events as young adults, whose early selection theoretically filters out half the stimuli that are presented in the ignore color. However, this does not explain why older participants generate robust electrophysiological markers of early selection based on color (SP and SN components) if they then do not utilize this information to carry out the task.

It is also possible that older participants execute task demands more cautiously than younger participants and therefore may engage in additional processing to confirm the outcome of earlier cognitive operations. In this case, it would mean reevaluating the products of early selection. Support for this account is derived from evidence that older individuals tend to trade speed for accuracy and have a higher threshold for considering a stimulus to be a target (Deakin, Aitken, Robbins, \& Sahakian, 2004; Brebion, 2001; Smith \& Brewer, 1995; Rabbitt, 1979). This increased caution may reflect a difference in temperament associated with an aversion to risk-taking or represent a voluntary, strategic choice to accumulate more evidence before making a decision (Deakin et al., 2004; Botwinick, 1966, 1978). Of note, there is growing support for the idea that age-associated increases in caution may be a consequence of structural changes in the brain, including alterations in functional connectivity (Han et al., 2012) and the degeneration of white matter tracts that allow information to be processed quickly and accurately and be transferred efficiently across nodes of a network (Forstmann et al., 2011).

Regardless of which hypothesis (e.g., slowed processing speed, degraded products of early selection, more cautious temperament) is most accurate, at the time in which late selection/decision-making takes place, greater uncertainty remains for older adults than their younger counterparts. In response to this uncertainty, they may carry out late selection based on the principle, "don't trust, verify." Despite exhibiting relative preservation of the size of electrophysiological markers of early selection, older adults continue to process or reprocess the stimuli to verify that they are carrying out task demands appropriately. This approach may come at a cost for older adults when faced with increased task demands because it depletes their limited processing resources.

There are several reasons why our results may differ from those reported by Gazzaley et al. (2008), who found that older participants exhibited an inhibitory deficit during early visual processing and no deficit during later processing. The Gazzaley et al. study concentrated on enhancement under an attend condition or suppression under an ignore condition as compared with responses under a passive condition, which was not the focus of the current study. In looking at Gazzaley et al.'s data, it is unclear whether there were age-associated differences in the overall modulation between the attend and ignore conditions in the markers they used for early selection. Additionally, age-related differences in early selection were not observed for the top-performing subgroup of old participants (assessed by median split), who executed the task as well as young participants, suggesting that performance and not age played an important role in the outcome (a result also found by Stormer, Li, Heekeren, \& Lindenberger, 2013, who investigated age-related differences in early visual attention to moving target stimuli in the face of distracters that were stationary or moving). Our study only included old participants with high executive capacity who performed comparably to young participants on the experimental task. Thus, the old participants in the current study may have been similar to the top-performing ones in the Gazzaley et al. investigation, who did not differ from their younger counterparts on measures of early selection. Finally, the study by Gazzaley et al. used alpha desynchronization as their measure of late processing, which was not analyzed in our investigation.

Several limitations of the current investigation deserve further comment. The study did not include multiple levels of task difficulty for each age group, which would have provided the opportunity to examine the impact of matching groups for either task performance or task demand. For example, one could question whether making the task harder for young than old adults was the reason they produced a larger $\mathrm{P} 3 \mathrm{~b}$ difference wave. However, this account seems unlikely. Consistent with other results in the literature (Miller, Rietschel, McDonald, \& Hatfield, 2011; Sawaki \& Katayama, 2006, 2008; Palmer, Nasman, \& Wilson, 1994), Mott et al. (2013) found when participants perform the current experimental paradigm, increasing task difficulty led to a reduction in the amplitude of the P3b under the attend condition, an effect that was not modulated by age. Therefore, making the task harder for young adult participants would tend to reduce the difference between attend and ignore 
conditions in P3b amplitude and thus does not explain their larger P3b difference wave. A related question is whether older participants would have produced a smaller SP and SN if they had participated in as difficult a task as young adults. This too seems unlikely. Zhuravleva et al. (2012) found that in older adults (65-80 years old), the size of the SP or SN was not smaller under high load (four target letters) than low load (one target letter). This result argues against the notion that the SP and SN diminishes as a function of task demand and that old adults would have generated smaller components than young participants if they had participated in a task with five target letters.

However, the impact of more demanding tasks on age-related differences in early and late selection remains an open question. Future research should examine the effects of augmented task requirements by varying working memory load or perceptual demands. Studies are needed to determine whether findings analogous to the ones reported here would be observed in tasks in which targets and distracters are presented simultaneously rather than sequentially. For example, many studies using Stroop or flanker paradigms have found that old participants generate less differentiated late ERP responses to congruent versus incongruent stimuli (Hsieh \& Fang, 2012; Wild-Wall, Falkenstein, \& Hohnsbein, 2008; Eppinger, Kray, Mecklinger, \& John, 2007; Kray, Eppinger, \& Mecklinger, 2005; West, 2004; West \& Alain, 2000). However, these studies have not explored whether delays or deficits in markers of earlier processing contribute to the age-related decline in indices of later conflict processing, which might be a fruitful avenue of investigation.

Future studies also need to replicate the current findings with a larger sample size to help ensure that the null effects of the SP and SN amplitudes were not a result of a lack of power. It is also important to determine the applicability of our findings to nonspatial features besides color. It remains to be determined if a similar pattern of age-related change is observed for participants in their mid-80s and beyond and to discover whether these changes begin as early as middle age. Other work should include older participants with average executive capacity to investigate whether the pattern of findings in the current study is specific to older adults with high executive function. Ideally, data would be collected from adults with low, average, and high executive capacity who participate in related selective attention experiments that systematically vary task requirements. This would offer the opportunity to compare subgroups matched according to task demands, task performance, and/or executive capacity, which could provide a much more textured account of cognitive aging.

\section{Acknowledgments}

This research was funded in part by NIA Grant R01 AGO17935 and by generous support from the Wimberly family, the Muss family, and the Mortimer/Grubman family. The authors would like to thank Christine Dunant and Marissa Keppley for their excellent administrative assistance.

Reprint requests should be sent to Kirk R. Daffner, Center for Brain/Mind Medicine, Division of Cognitive and Behavioral Neurology, Brigham and Women's Hospital, Harvard Medical School, 221 Longwood Avenue, Boston, MA 02115, or via e-mail: kdaffner@partners.org.

\section{Notes}

1. Only the attend condition was used to compute the P3b latency because both young and old participants demonstrated a robust $\mathrm{P} 3 \mathrm{~b}$ to target stimuli under the attend condition. Because young participants exhibited a muted $\mathrm{P} 3 \mathrm{~b}$ response to target letter forms under the ignore condition, it would have been inappropriate to measure a latency value.

2. Because of preceding ERP components, the onset of the $\mathrm{P} 3 \mathrm{~b}$ did not start at $0 \mu \mathrm{V}$. Therefore, the value of the mean amplitude between 300 and $350 \mathrm{msec}$ was used as a baseline and subtracted from the subsequent 25-msec epochs. The 300350 msec epoch was chosen as the baseline based on visual inspection of grand average plots (see Figure 8).

3. We also found an effect of Age Group, $F(2,40)=11.90, p<$ .001 , which was present because the mean amplitude collapsed across attend and ignore conditions was larger for old participants than for young participants. However, most pertinent to the goals of the current study was finding that the difference in the size of the response under the attend and ignore conditions did not vary across age groups.

4. Our focus was on the SP and SN responses to standard stimuli. However, following the same procedures described in the Methods section, we also examined the SP and SN in response to target stimuli. The pattern of results was the same as in response to standard stimuli (i.e., the size of the SP and $\mathrm{SN}$ to target stimuli did not differ across age groups).

5. Age group differences were also found when the peak latency of the P3b was measured at either midline electrode sites $\mathrm{Cz}$ and Pz $(p<.001)$ or posterior ROIs LPM and RPM $(p<.05)$. 6. There is strong evidence for what has been characterized as an age-related anterior shift in the scalp distribution of the P3b component (Fabiani, Friedman, \& Cheng, 1998; Friedman, Kazmerski, \& Fabiani, 1997). To show that our findings were not merely a reflection of an age-associated shift in P3b scalp distribution, analyses were also run for the anterior medial and posterior medial ROIs LAM, RAM, LPM, and RPM. Similar results were found: young-high and young-average participants showed a differentiated response between attend and ignore stimuli (A > I, $F(1,12)=35.14, p<.001$ and $F(1,12)=12.41$, $p=.004$, respectively) whereas older participants did not $(\mathrm{A}=\mathrm{I}$, $F(1,16)=1.57, p=.23)$.

7. Of note, when controlling for multiple comparisons for the SP early intervals (Bonferroni correction $p<.017$ ), the correlations for the 150-175 msec and 150-200 msec epochs remain significant whereas the correlation for the 175-200 msec epoch becomes marginal. When controlling for age, the correlations for the 150-175 msec and 150-200 msec epochs become marginal.

8. In contrast to many reports, Talsma et al. (2006) found that in an experiment involving selective attention to gratings with different spatial frequencies, older adults produced a more differentiated $\mathrm{P} 3 \mathrm{~b}$ response to attend and ignore stimuli than young adults. However, contrary to our study and others, they measured $\mathrm{P} 3 \mathrm{~b}$ in response to standard rather than target events. They also found that the old participants generated a much larger $\mathrm{P} 3 \mathrm{~b}$ response to standard stimuli than did young participants. Such a result may be another reflection of the 
reduced ability of older adults to limit resources allocated to the processing of nonsalient (i.e., standard) events (Hahn et al., 2011; Curran et al., 2001; Kenemans et al., 1995; Looren de Jong et al., 1988).

9. We ran exploratory analyses to test whether there were age-related differences in the extent to which participants make an early, preliminary discrimination between letter forms (target vs. standard letters). The target-standard difference waves during the temporal interval of the SP and SN were analyzed and revealed that neither the size of the SP nor SN was modulated by age for the attend condition $(p>.76$ and $p>.61$, respectively) or the ignore condition $(p>.64$ and $p>.48$, respectively). This suggests that young and old adults do not differ in the degree to which they process letters during early selection.

\section{REFERENCES}

American Psychiatric Association. (1994). Diagnostic and statistical manual of mental disorders (4th ed.). Washington, DC: American Psychological Association.

Anderer, P., Semlitsch, H. V., \& Saletu, B. (1996). Multichannel auditory event-related brain potentials: Effects of normal aging on the scalp distribution of N1, P2, N2 and P300 latencies and amplitudes. Electroencephalography and Clinical Neurophysiology, 99, 458-472.

Anguera, J. A., \& Gazzaley, A. (2012). Dissociation of motor and sensory inhibition processes in normal aging. Clinical Neurophysiology, 123, 730-740.

Baltes, P. B., \& Lindenberger, U. (1997). Emergence of a powerful connection between sensory and cognitive functions across the adult life span: A new window to the study of cognitive aging? Psychology and Aging, 12, 12-21.

Beck, A. T., \& Steer, R. A. (1987). Beck depression inventory: Manual. San Antonio, TX: The Psychological Corporation.

Botwinick, J. (1966). Cautiousness in advanced age. Journal of Gerontology, 21, 347-353.

Botwinick, J. (1978). Aging and behavior (2nd ed.). New York: Springer Publishing Company, Inc.

Braver, T. S., Barch, D. M., Keys, B. A., Carter, C. S., Cohen, J. D., Kaye, J. A., et al. (2001). Context processing in older adults: Evidence for a theory relating cognitive control to neurobiology in healthy aging. Journal of Experimental Psychology: General, 130, 746-763.

Brebion, G. (2001). Language processing, slowing, and speed/accuracy trade-off in the elderly. Experimental Aging Research, 27, 137-150.

Broadbent, D. E. (1970). Stimulus set and response set: Two kinds of selective attention. In D. I. Mostofsky (Ed.), Attention: Contemporary theory and analysis (pp. 51-60). New York: Appleton.

Chan, R. C., Shum, D., Toulopoulou, T., \& Chen, E. Y. (2008). Assessment of executive functions: Review of instruments and identification of critical issues. Archives of Clinical Neuropsychology, 23, 201-216.

Curran, T., Hills, A., Patterson, M. B., \& Strauss, M. E. (2001). Effects of aging on visuospatial attention: An ERP study. Neuropsychologia, 39, 288-301.

Czigler, I. (1996). Age, color processing and meaningfulness: An event-related potential study. International Journal of Psychophysiology, 22, 25-34.

Daffner, K. R., Chong, H., Riis, J., Rentz, D. M., Wolk, D. A., Budson, A. E., et al. (2007). Cognitive status impacts age-related changes in attention to novel and target events in normal adults. Neuropsychology, 21, 291-300.

Daffner, K. R., Chong, H., Sun, X., Tarbi, E. C., Riis, J. L., McGinnis, S. M., et al. (2011). Mechanisms underlying age- and performance-related differences in working memory. Journal of Cognitive Neuroscience, 23, 1298-1314.

Daffner, K. R., Ryan, K. K., Williams, D. M., Budson, A. E., Rentz, D. M., Wolk, D. A., et al. (2006). Increased responsiveness to novelty is associated with successful cognitive aging. Journal of Cognitive Neuroscience, 18, 1759-1773.

Daffner, K. R., Sun, X., Tarbi, E., Rentz, D. M., Holcomb, P. J., \& Riis, J. L. (2011). Does compensatory neural activity survive old-old age? Neuroimage, 54, 427-438.

Daffner, K. R., Tarbi, E. C., Haring, A. E., Zhuravleva, T. Y., Sun, X., Rentz, D. M., et al. (2012). The influence of executive capacity on selective attention and subsequent processing. Frontiers in Human Neuroscience, 6, 167.

Daffner, K. R., Zhuravleva, T. Y., Sun, X., Tarbi, E. C., Haring, A. E., Rentz, D. M., et al. (2012). Does modulation of selective attention to features reflect enhancement or suppression of neural activity? Biological Psychology, 89, 398-407.

Daselaar, S. M., \& Cabeza, R. (2005). Age-related changes in hemispheric organization. In R. Cabeza, L. Nyberg, \& D. C. Park (Eds.), Cognitive neuroscience of aging (pp. 325-353). New York: Oxford University Press.

Davis, S. W., Dennis, N. A., Daselaar, S. M., Fleck, M. S., \& Cabeza, R. (2008). Que pasa? The posterior-anterior shift in aging. Cerebral Cortex, 18, 1201-1209.

de Fockert, J. W., Ramchurn, A., van Velzen, J., Bergstrom, Z., \& Bunce, D. (2009). Behavioral and ERP evidence of greater distractor processing in old age. Brain Research, 1282, 67-73.

de Fockert, J. W., Rees, G., Frith, C. D., \& Lavie, N. (2001). The role of working memory in visual selective attention. Science, 291, 1803-1806.

Deakin, J., Aitken, M., Robbins, T., \& Sahakian, B. J. (2004). Risk taking during decision-making in normal volunteers changes with age. Journal of the International Neuropsychological Society, 10, 590-598.

Delis, D., Kaplan, E., \& Kramer, J. (2001). Delis Kaplan executive function system. San Antonio, TX: Psychological Cooperation.

Delorme, A., \& Makeig, S. (2004). EEGLAB: An open source toolbox for analysis of single-trial EEG dynamics including independent component analysis. Journal of Neuroscience Methods, 134, 9-21.

Desimone, R., \& Duncan, J. (1995). Neural mechanisms of selective visual attention. Annual Review of Neuroscience, 18, 193-222.

Donchin, E., \& Coles, M. G. H. (1988). Is the P300 component a manifestation of context updating? Behavioral and Brain Sciences, 11, 357-374.

Eppinger, B., Kray, J., Mecklinger, A., \& John, O. (2007). Age differences in task switching and response monitoring: Evidence from ERPs. Biological Psychology, 75, 52-67.

Fabiani, M., Friedman, D., \& Cheng, J. C. (1998). Individual differences in P3 scalp distribution in older adults, and their relationship to frontal lobe function. Psychophysiology, 35, 698-708.

Fjell, A. M., \& Walhovd, K. B. (2004). Life-span changes in P3a. Psychophysiology, 41, 575-583.

Folstein, M. F., Folstein, S. E., \& McHugh, P. R. (1975). "Mini-mental state". A practical method for grading the cognitive state of patients for the clinician. Journal of Psychiatric Research, 12, 189-198.

Forstmann, B. U., Tittgemeyer, M., Wagenmakers, E. J., Derrfuss, J., Imperati, D., \& Brown, S. (2011). The speed-accuracy tradeoff in the elderly brain: A structural model-based approach. Journal of Neuroscience, 31, $17242-17249$ 
Friedman, D., Kazmerski, V., \& Fabiani, M. (1997). An overview of age-related changes in the scalp distribution of P3b. Electroencephalography and Clinical Neurophysiology, 104, 498-513.

Gazzaley, A., Clapp, W., Kelley, J., McEvoy, K., Knight, R. T., \& D’Esposito, M. (2008). Age-related top-down suppression deficit in the early stages of cortical visual memory processing. Proceedings of the National Academy of Sciences, U.S.A., 105, 13122-13126.

Gazzaley, A., Cooney, J. W., Rissman, J., \& D’Esposito, M. (2005). Top-down suppression deficit underlies working memory impairment in normal aging. Nature Neuroscience, 8, 1298-1300.

Ghisletta, P., \& de Ribaupierre, A. (2005). A dynamic investigation of cognitive dedifferentiation with control for retest: Evidence from the Swiss interdisciplinary longitudinal study on the oldest old. Psychology and Aging, 20, 671-682.

Hahn, M., Wild-Wall, N., \& Falkenstein, M. (2011). Age-related differences in performance and stimulus processing in dual task situation. Brain Research, 1414, 66-76.

Han, S. D., Boyle, P. A., Arfanakis, K., Fleischman, D. A., Yu, L., Edmonds, E. C., et al. (2012). Neural intrinsic connectivity networks associated with risk aversion in old age. Behavioural Brain Research, 227, 233-240.

Haring, A. E., Zhuravleva, T. Y., Alperin, B. R., Rentz, D. M., Holcomb, P. J., \& Daffner, K. R. (2013). Age-related differences in enhancement and suppression of neural activity underlying selective attention in matched young and old adults. Brain Research, 1499, 69-79.

Harter, R. M., \& Aine, C. J. (1984). Brain mechanisms of visual selective attention. In R. Parasuraman \& D. R. Davies (Eds.), Varieties of attention (pp. 293-321). Orlando: Academic Press Inc.

Hasher, L., \& Zacks, R. T. (1988). Working memory, comprehension, and aging: A review and a new view. Psychology of Learning \& Motivation, 22, 193-225.

Hillyard, S. A., \& Munte, T. F. (1984). Selective attention to color and location: An analysis with event-related brain potentials. Perception and Psychophysics, 36, 185-198.

Hillyard, S. A., Teder-Salejarvi, W. A., \& Munte, T. F. (1998). Temporal dynamics of early perceptual processing. Current Opinion in Neurobiology, 8, 202-210.

Hsieh, S., \& Fang, W. (2012). Elderly adults through compensatory responses can be just as capable as young adults in inhibiting the flanker influence. Biological Psychology, 90, 113-126.

Ivnik, R. J., Malec, J. F., Smith, G. E., Tangalos, E. G., \& Petersen, R. C. (1996). Neuropsychological tests' norms above age 55: COWAT, BNT, MAE Token, WRAT-R Reading, AMNART, Stroop, TMT, and JLO. The Clinical Neuropsychologist, 10, 262-278.

Kenemans, J. L., Smulders, F. T., \& Kok, A. (1995). Selective processing of two-dimensional visual stimuli in young and old subjects: Electrophysiological analysis. Psychophysiology, 32, 108-120.

Kok, A. (2001). On the utility of P3 amplitude as a measure of processing capacity. Psychophysiology, 38, 557-577.

Kopp, B., Tabeling, S., Moschner, C., \& Wessel, K. (2007). Temporal dynamics of selective attention and conflict resolution during cross-dimensional go-nogo decisions. BMC Neuroscience, 8, 68-83.

Kramer, A. F., Humphrey, D. G., Larish, J. F., Logan, G. D., \& Strayer, D. L. (1994). Aging and inhibition: Beyond a unitary view of inhibitory processing in attention. Psychology and Aging, 9, 491-512.

Kray, J., Eppinger, B., \& Mecklinger, A. (2005). Age differences in attentional control: An event-related potential approach. Psychophysiology, 42, 407-416.
Lavie, N., Hirst, A., de Fockert, J. W., \& Viding, E. (2004). Load theory of selective attention and cognitive control. Journal of Experimental Psychology: General, 133, 339-354.

Li, S. C., \& Lindenberger, U. (1999). Cross-level unification: A computational exploration of the link between deterioration of neurotransmitter systems and dedifferentiation of cognitive abilities in old age. In L. G. Nilsson \& H. J. Markowitsch (Eds.), Cognitive neuroscience of memory (pp. 103-146). Seattle: Hogrefe \& Huber.

Looren de Jong, H., Kok, A., \& van Rooy, J. C. (1988). Early and late selection in young and old adults: An event-related potential study. Psychophysiology, 25, 657-671.

Lorenzo-Lopez, L., Amenedo, E., Pazo-Alvarez, P., \& Cadaveira, F. (2007). Visual target processing in high- and low-performing older subjects indexed by P3 component. Neurophysiologie Clinique, 37, 53-61.

Luck, S. J. (2005). An introduction to the event-related potential technique. Cambridge, MA: The MIT Press.

Luck, S. J., \& Hillyard, S. A. (1994). Electrophysiological correlates of feature analysis during visual search. Psychophysiology, 31, 291-308.

Lustig, C., Hasher, L., \& Zacks, R. T. (2007). Inhibitory deficit theory: Recent developments in a "new view". In D. S. Gorfein \& C. M. Macleod (Eds.), Inbibition in cognition (pp. 145-162). Washington, DC: American Psychological Association.

McCarthy, G., \& Donchin, E. (1981). A metric for thought: A comparison of $\mathrm{P} 300$ latency and reaction time. Science, 211, 77-80.

McDowd, J. M., \& Filion, D. L. (1992). Aging, selective attention, and inhibitory processes: A psychophysiological approach. Psychology and Aging, 7, 65-71.

McGinnis, E. M., \& Keil, A. (2011). Selective processing of multiple features in the human brain: Effects of feature type and salience. PloS One, 6, e16824.

Milham, M. P., Erickson, K. I., Banich, M. T., Kramer, A. F., Webb, A., Wszalek, T., et al. (2002). Attentional control in the aging brain: Insights from an fMRI study of the Stroop task. Brain and Cognition, 49, 277-296.

Miller, M. W., Rietschel, J. C., McDonald, C. G., \& Hatfield, B. D. (2011). A novel approach to the physiological measurement of mental workload. International Journal of Psychophysiology, 80, 75-78.

Mott, K., Alperin, B., Zhuravleva, T., Holcomb, P., Rentz, D., \& Daffner, K. (2013). Age-related reduction of differentiated neural responses to different stimulus types. Supplement of the Journal of Cognitive Neuroscience: Cognitive Neuroscience Society, Annual Meeting Program, 151.

Muller, M. M., \& Keil, A. (2004). Neuronal synchronization and selective color processing in the human brain. Journal of Cognitive Neuroscience, 16, 503-522.

Näätänen, R. (1992). Attention and brain function. Hillsdale, NJ: Erlbaum.

Palmer, B., Nasman, V. T., \& Wilson, G. F. (1994). Task decision difficulty: Effects on ERPs in a same-different letter classification task. Biological Psychology, 38, 199-214.

Park, D. C., \& Reuter-Lorenz, P. (2009). The adaptive brain: Aging and neurocognitive scaffolding. Annual Review of Psychology, 60, 173-196.

Potts, G. F., \& Tucker, D. M. (2001). Frontal evaluation and posterior representation in target detection. Brain Research: Cognitive Brain Research, 11, 147-156.

Rabbitt, P. (1979). How old and young subjects monitor and control responses for accuracy and speed. British Journal of Psychology, 70, 305-311.

Reitan, R., \& Wolfson, D. (1985). The Halstead-Reitan neuropsychological test battery: Theory and clinical interpretation. Tucson, AZ: Neuropsychology Press. 
Riis, J. L., Chong, H., McGinnnis, S., Tarbi, E., Sun, X., Holcomb, P. J., et al. (2009). Age-related changes in early novelty processing as measured by ERPs. Biological Psychology, $82,33-44$

Riis, J. L., Chong, H., Ryan, K. K., Wolk, D. A., Rentz, D. M., Holcomb, P. J., et al. (2008). Compensatory neural activity distinguishes different patterns of normal cognitive aging. Neuroimage, 39, 441-454.

Rissman, J., Gazzaley, A., \& D'Esposito, M. (2009). The effect of non-visual working memory load on top-down modulation of visual processing. Neuropsychologia, 47, 1637-1646.

Rutman, A. M., Clapp, W. C., Chadick, J. Z., \& Gazzaley, A. (2010). Early top-down control of visual processing predicts working memory performance. Journal of Cognitive Neuroscience, 22, 1224-1234.

Ryan, J., \& Paolo, A. (1992). A screening procedure for estimating premorbid intelligence in the elderly. The Clinical Neuropsychologist, 6, 53-62.

Salthouse, T. A. (1996). The processing-speed theory of adult age differences in cognition. Psychological Review, 103, 403-428.

Sawaki, R., \& Katayama, J. (2006). Stimulus context determines whether non-target stimuli are processed as task-relevant or distractor information. Clinical Neurophysiology, 117, 2532-2539.

Sawaki, R., \& Katayama, J. (2008). Distractor P3 is associated with attentional capture by stimulus deviance. Clinical Neurophysiology, 119, 1300-1309.

Sirevaag, E. J., Kramer, A. F., Coles, M. G., \& Donchin, E. (1989). Resource reciprocity: An event-related brain potentials analysis. Acta Psychologica, 70, 77-97.

Smith, G. A., \& Brewer, N. (1995). Slowness and age: Speed-accuracy mechanisms. Psychology and Aging, 10, 238-247.

Spreen, O., \& Strauss, E. (1998). In O. Spreen \& E. Strauss (Eds.), A compendium of neuropsychological tests: Administration, norms, and commentary (2nd ed., vol. 599). New York: Oxford University Press.

Stormer, V. S., Li, S. C., Heekeren, H. R., \& Lindenberger, U. (2013). Normal aging delays and compromises early multifocal visual attention during object tracking. Journal of Cognitive Neuroscience, 25, 188-202.

Talsma, D., Kok, A., \& Ridderinkhof, K. R. (2006). Selective attention to spatial and non-spatial visual stimuli is affected differentially by age: Effects on event-related brain potentials and performance data. International Journal of Psychophysiology, 62, 249-261.

van der Stelt, O., Kok, A., Smulders, F. T., Snel, J., \& Boudewijn Gunning, W. (1998). Cerebral event-related potentials associated with selective attention to color:
Developmental changes from childhood to adulthood. Psychophysiology, 35, 227-239.

Vogel, E. K., McCollough, A. W., \& Machizawa, M. G. (2005). Neural measures reveal individual differences in controlling access to working memory. Nature, 438, 500-503

Voss, M. W., Erickson, K. I., Chaddock, L., Prakash, R. S., Colcombe, S. J., Morris, K. S., et al. (2008). Dedifferentiation in the visual cortex: An fMRI investigation of individual differences in older adults. Brain Research, 1244, 121-131.

Wechsler, D. (2008). Wechsler Adult Intelligence Scale (4th ed.). San Antonio, TX: Pearson.

West, R. (1999). Visual distraction, working memory, and aging. Memory and Cognition, 27, 1064-1072.

West, R. (2004). The effects of aging on controlled attention and conflict processing in the Stroop task. Journal of Cognitive Neuroscience, 16, 103-113.

West, R., \& Alain, C. (2000). Age-related decline in inhibitory control contributes to the increased Stroop effect observed in older adults. Psychophysiology, 37, 179-189.

Wickens, C., Kramer, A., Vanasse, L., \& Donchin, E. (1983). Performance of concurrent tasks: A psychophysiological analysis of the reciprocity of information-processing resources. Science, 221, 1080-1082.

Wijers, A. A., Mulder, G., Okita, T., Mulder, L. J., \& Scheffers, M. K. (1989). Attention to color: An analysis of selection, controlled search, and motor activation, using event-related potentials. Psychophysiology, 26, 89-109.

Wild-Wall, N., Falkenstein, M., \& Hohnsbein, J. (2008). Flanker interference in young and older participants as reflected in event-related potentials. Brain Research, 1211, 72-84.

Yesavage, J. A., Brink, T. L., Rose, T. L., Lum, O., Huang, V., Adey, M., et al. (1982). Development and validation of a geriatric depression screening scale: A preliminary report. Journal of Psychiatric Research, 17, 37-49.

Zanto, T. P., Hennigan, K., Ostberg, M., Clapp, W. C., \& Gazzaley, A. (2010). Predictive knowledge of stimulus relevance does not influence top-down suppression of irrelevant information in older adults. Cortex, 46, 564-574.

Zanto, T. P., Rubens, M. T., Thangavel, A., \& Gazzaley, A. (2011). Causal role of the prefrontal cortex in top-down modulation of visual processing and working memory. Nature Neuroscience, 14, 656-661.

Zhuravleva, T., Haring, A., Alperin, B., Holcomb, P., Rentz, D., \& Daffner, K. (2012). Age-related changes in selective attention in the very old: A bottom-up or top-down problem? Supplement of the Journal of Cognitive Neuroscience: Cognitive Neuroscience Society, Annual Meeting Program, 61. 